\title{
Key Stratum Structure and Support Working Resistance of Longwall Face with Large Mining Height in the Shallow Coal Seams, China
}

\author{
Qingxiang Huang $\mathbb{D}^{1},{ }^{1}$ Jinlong Zhou $\mathbb{D}^{1},{ }^{1,2}$ and Jian Cao ${ }^{1}$ \\ ${ }^{1}$ School of Energy Engineering, Xi'an University of Science and Technology, Xi'an 710054, Shaanxi, China \\ ${ }^{2}$ School of Energy and Mining Engineering, China University of Mining and Technology, Beijing 100083, China \\ Correspondence should be addressed to Qingxiang Huang; huangqx@xust.sn.cn and Jinlong Zhou; zhoujlcumtb@163.com
}

Received 1 July 2020; Accepted 24 September 2020; Published 31 October 2020

Academic Editor: Jiang Jin

Copyright (c) 2020 Qingxiang Huang et al. This is an open access article distributed under the Creative Commons Attribution License, which permits unrestricted use, distribution, and reproduction in any medium, provided the original work is properly cited.

\begin{abstract}
The fully mechanized mining with large mining height is the main method for high yield and efficient coal mining in China. The key stratum structure (KSS) is the basis of revealing the mechanism of roof weighting and determination of support working resistance of the longwall face with large mining height (LFLMH) in the shallow coal seam. The height of the caving zone at LFLMH is large, the thick immediate roof forms the "short cantilever beam" structure commonly, and the hinge layer of the overlying key stratum will move upward to the higher position. The "high position oblique step voussoir beam" structure of singlekey stratum (SKS) and "oblique step voussoir beam and voussoir beam" structure of double-key stratum (DKS) in the shallow coal seam were proposed with physical simulation and Universal Distinct Element Code (UDEC). The analysis of the KSS and numerical simulation reveals the mechanism of strong roof weighting at the SKS longwall face and large-small alternate periodic weighting at the DKS longwall. It is concluded that the large static load caused by the "equivalent immediate roof (EIR)" is the basic load, and the instability load of the KSS is the additional dynamic load of support. Besides, the calculation methods of the reasonable support working resistance at LFLMH were obtained and verified with engineering applications.
\end{abstract}

\section{Introduction}

The reserves of thick coal seams contribute about $44 \%$ of the country's total coal reserves, and the coal thereof produced accounts for approximately $45 \%$ of the total raw coal output in China $[1,2]$, indicating that the safe and efficient mining of thick coal seams is critical to Chinese energy supply. Shenfu-Dongsheng Coalfield, as depicted in Figure 1, is one of the largest coal production coalfields worldwide, and there are a large number of coal seams characterized by the shallow cover and extreme thickness in the northwest of China [3]. Fully mechanized mining with large mining height technology with the advantages of high coal recovery rate and low roadway driving rate has been the common method for high-efficiency coal mining with the thickness of coal seam ranging from 3.5 to $8 \mathrm{~m}$ in China $[1,4-6]$. China is also the country with the most coal mine accidents in the world $[7,8]$, including the coal wall falls, roof falls, coal burst, and support failure accidents, affecting coal production and its efficiency seriously [9-12]. In 2017, 375 people died of coal mine disasters, where $32 \%$ are roof accidents, indicating that it is quite essential to ensure the roof stability for the safety of mining workers and equipment [8]. It is an essential issue to find out the mechanism of roof instability and determine the effective support working resistance for the longwall face in the shallow thick seams [13].

With the development of the Shendong Coalfield, Chinese scholars have conducted systematic studies on the KSS and the theory of ground control in the shallow coal seam. The "key stratum theory" [14] provides a new approach to study the KSS and mine pressure behaviors, where 


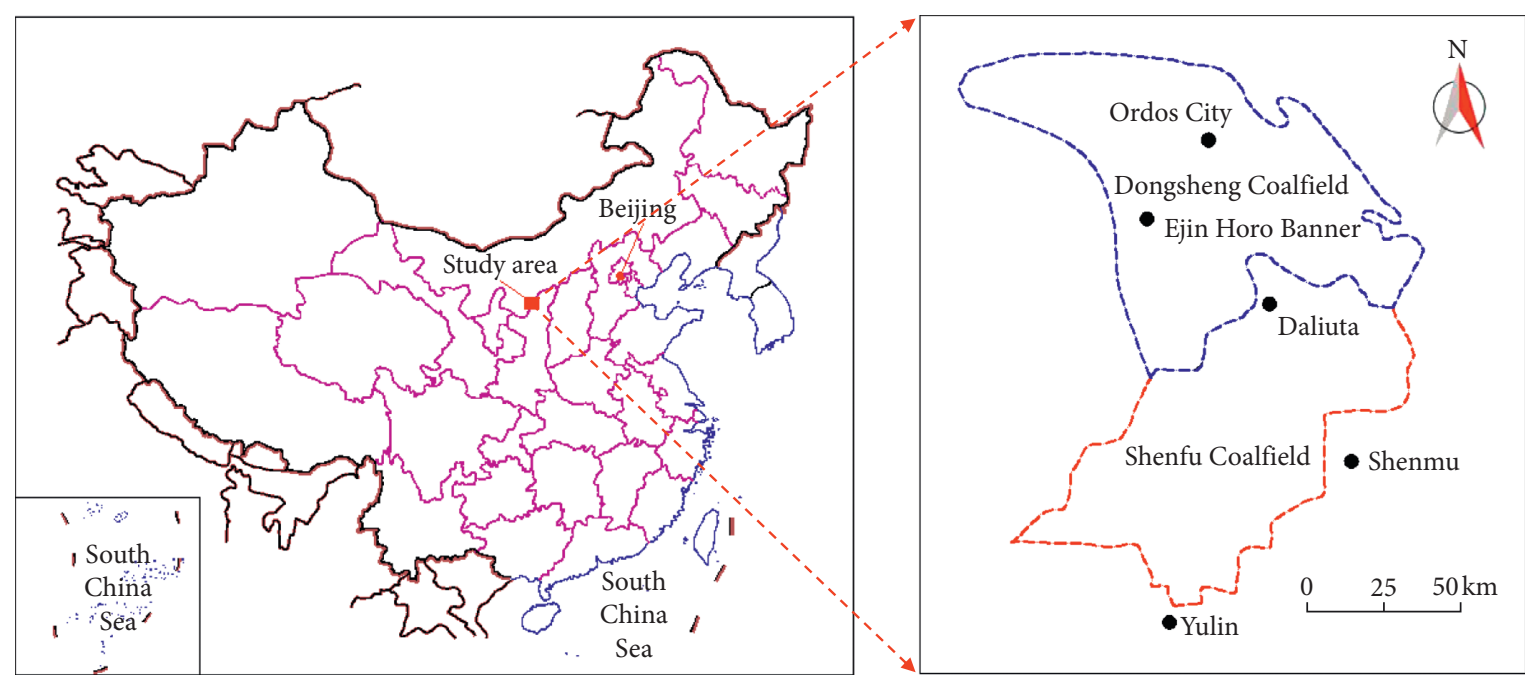

Figure 1: The location of Shenfu-Dongsheng Coalfield in China.

the stratum that controls the movement of part or all of the overlying strata was defined as the key stratum (KS). Huang has proposed the "asymmetric three-hinged arches" structure of the roof in the first weighting [15], the "short voussoir beam" and "step voussoir beam" structures of the roof in the periodic weighting [16], and the load transfer theory of unconsolidated layers [17]. All these provide the theoretical basis for the roof control in shallow coal seam mining.

In recent years, with the rapid development of large mining height mining equipment and technology, the maximum mining height has reached $8.8 \mathrm{~m}$ in Shendong Coalfield, China, the mine pressure behaviors of the longwall face are strong, and the roof control is complicated. The relationship between support and surrounding rock at LFLMH has become a study hotspot. Ju and $\mathrm{Xu}$ have analyzed the structural characteristics of key stratum and strata behavior of the longwall face with super large mining height [18] and proposed the "cantilever beam and voussoir beam" structure, which leads to the alternating roof pressure [19]. Yan et al. [20] have proposed the "short cantilever beam and articulated voussoir beam" structure at LFLMH and found that the fracture interval of the roof has a significant influence on the support working resistance. Based on the statistical analysis for field measurements of support load at the longwall faces with 3.5 to $5.5 \mathrm{~m}$ mining height, Gong [21] has revealed that the influence of the main roof structure on the support load decreases, and the influence of the immediate roof on the support load increases. Huang et al. have proposed the concept of EIR [22] and the "oblique step voussoir beam" structure at LFLMH [23] and studied the crack development characteristics under different mining conditions in the shallow coal seam [24]. The abovementioned studies have promoted the development of roof control at LFLMH. However, the effect of filling status of the goaf on SKS and DKS structures in the shallow coal seam still needs to be studied because the immediate roof has a significant impact on the stability of the KSS and roof control at LFLMH. A clear scientific understanding of the KSS and roof weighting mechanism of LFLMH in the shallow coal seam is still lacking.

This study constructed the mechanical models of SKS and DKS roof structures at LFLMH and revealed the mechanism of roof weighting of the longwall face and proposed the calculation methods of the reasonable support working resistance. We wish that the study's results are used as a reference for roof control at LFLMH in the shallow coal seam.

\section{Caving Characteristics of the Immediate Roof at LFLMH}

The height of the caving zone at LFLMH increases linearly with the increase of mining height [13, 25-27]; the hinge layer of overlying strata moves upward in the higher position. In this part, the caving characteristics of the immediate roof were studied using the physical simulation experiment.

2.1. Geological Conditions. The physical simulation experiment was based on the mining conditions of No. 5-2 seam in Zhangjiamao coal mine, located in Yulin, Shaanxi, China. The No. 5-2 seam belongs to a typical shallow coal seam with average depth and thickness of $120 \mathrm{~m}$ and $6.1 \mathrm{~m}$. The roof of No. 5-2 seam is mainly made up of the siltstone, the fine grained sandstone, and the overlying strata with thin bedrock and thick unconsolidated layers. The composite histogram of No. 5-2 seam is shown in Figure 2.

2.2. Physical Simulation Analysis. Physical simulation is one of the most effective techniques in research on rock strata behavior [28-30], which has been applied to simulate longwall mining-induced subsidence and other related problems [31-33]. Due to the difference in scale between coal fields and laboratory experiments, proper model materials must be selected to maintain meaningful physical proportions to the field conditions. The properties of model 


\begin{tabular}{|c|c|c|c|c|}
\hline No. & $\begin{array}{c}\text { Thickness } \\
(\mathrm{m})\end{array}$ & $\begin{array}{c}\text { Depth } \\
(\mathrm{m})\end{array}$ & $\begin{array}{c}\text { Stratigraphic } \\
\text { Column }\end{array}$ & Lithology \\
\hline 1 & 8.00 & 8.00 & $\cdots$ & Loess \\
\hline 2 & 42.40 & 50.40 \\
\hline 3 & 7.80 & 58.20 \\
\hline 4 & 4.09 & 62.29 \\
\hline 5 & 3.21 & 65.50 \\
\hline 6 & 0.50 & 66.00 \\
\hline 7 & 4.60 & 70.60 \\
\hline 8 & 10.62 & 81.22 \\
\hline 9 & 0.65 & 81.87 \\
\hline 10 & 5.95 & 87.82 \\
\hline 11 & 2.78 & 90.60 \\
\hline 12 & 4.36 & 94.96 \\
\hline 13 & 12.39 & 107.35 \\
\hline 14 & 1.19 & 108.54 \\
\hline 15 & 1.91 & 110.45 \\
\hline 16 & 1.67 & 112.12 \\
\hline 17 & 1.78 & 113.90 \\
\hline 18 & 2.60 & 116.50 \\
\hline 19 & 2.80 & 119.30 \\
\hline 20 & 6.10 & 125.40 \\
\hline 21 & 30.00 & 155.40 \\
\hline
\end{tabular}

FIGURE 2: Composite histogram of No. 5-2 seam.

material need to be tested to satisfy the similarity theory principles [32,34]. According to similarity theory and field conditions, the physical simulation model was built with the dimensions of $5 \mathrm{~m} \times 0.2 \mathrm{~m} \times 1.2 \mathrm{~m}$, the geometric ratio of the simulation model was determined as $1: 50$, the bulk density ratio is $1: 1.5$, and the strength ratio is $1: 75$; the overlying strata that the model has not simulated were replaced by the additional loads on the top of the model. The caving characteristics of the immediate roof were simulated with the mining height of $4 \mathrm{~m}, 5 \mathrm{~m}, 6 \mathrm{~m}$, and $7 \mathrm{~m}$ on the same model, as shown in Figure 3. The material ratio of the physical simulation model is listed in Table 1 based on the rock mechanics property tests.

Notes: A, B, C, and D are the longwall faces simulation areas with the mining height of $4 \mathrm{~m}, 5 \mathrm{~m}, 6 \mathrm{~m}$, and $7 \mathrm{~m}$, respectively.

The physical simulation results show that the thickness of the immediate roof at LFLMH is large. The immediate roof will not cave immediately after coal mining and form the "short cantilever beam" structure (Figure 4(a)). With the continued advance of the longwall face, the immediate roof will cave (Figure 4(b)). Some lower main roofs cannot form the hinged structure, but they can cave and fill the goaf to act as the "immediate roof." The strata below the KS that cannot form the hinged structure is defined as the EIR [22].

According to the physical simulation results, when the mining heights are $4 \mathrm{~m}, 5 \mathrm{~m}, 6 \mathrm{~m}$, and $7 \mathrm{~m}$, the thicknesses of EIR is $10 \mathrm{~m}, 15 \mathrm{~m}, 21 \mathrm{~m}$, and $26 \mathrm{~m}$, respectively, as shown in Figure 5 . The thickness of the EIR linearly correlates with mining height.
2.3. Classification of the EIR. When the thick EIR fractures, a large static load will be generated on the support, and the load is needed to be controlled by support setting load. The different filling status of the goaf will cause different stability of KSS and the strength of the roof weighting at the longwall face.

Based on the physical simulation results, the field observations of step subsidence [3], and the KS theory [14], the EIR can be divided into "fully filling type" and "general filling type." The "step voussoir beam" structure can be formed in general filling type, and it is the universal type of overlying strata during the shallow coal seam mining.

(1) Fully Filling Type. The thickness of the EIR is over 3 to 3.3 times the mining height. Under these conditions, the rotation space of the main roof structure is small; thus, the main roof can form the "voussoir beam" structure.

(2) General Filling Type. When the EIR cannot fully fill the goaf, the main roof structure will present step subsidence and form the "step voussoir beam" structure. Such thickness of EIR is generally less than 3 times the mining height, which is a universal condition at LFLMH. The "step voussoir beam" structure is prone to sliding instability [16]; the roof pressure of the "step voussoir beam" structure is larger than the roof pressure of the "voussoir beam" structure. Therefore, the determination of support working resistance should be based on this KSS.

\section{Numerical Simulation of the KSS}

3.1. Numerical Model Establishment. The No. 15201 LFLMH (LW15201) at Zhangjiamao coal mine and the No. 22303 LFLMH (LW22303) at Bulianta coal mine are taken as the background to study the overlying strata structure and mechanism of roof weighting at LFLMH in the shallow coal seam. The UDEC numerical models were established with the Mohr-Coulomb failure criterion to study the overlying strata structure during the advance of the longwall face. The lateral boundaries are fixed in displacement at the horizontal direction, the bottom boundary is fixed in displacement at the horizontal and vertical directions, and the top boundary is free. The dimensions of the two models were $500 \mathrm{~m}$ in length $\times 120 \mathrm{~m}$ in height and $500 \mathrm{~m}$ in length $\times 172 \mathrm{~m}$ height, respectively. The $100 \mathrm{~m}$ boundary coal pillars were set at the left and right ends of the models. The length of the simulation mining region is $300 \mathrm{~m}$ in the middle of the model.

The reasonable parameter setting and meshing are crucial to ensure the accuracy of the simulation results. Mohammad et al. [35] have suggested that the stiffness of the numerical model should be equal to 0.47 times the average stiffness value of the laboratory tests. Cai et al. [36] have suggested that the elastic modulus of coal and rocks should be 0.1 to 0.25 times that of the laboratory tests, while Poisson's ratio of coal and rocks is assumed to be 1.2 to 1.4 times that of the laboratory tests. Therefore, the elastic modulus and tensile strength of coal and rocks are equal to 


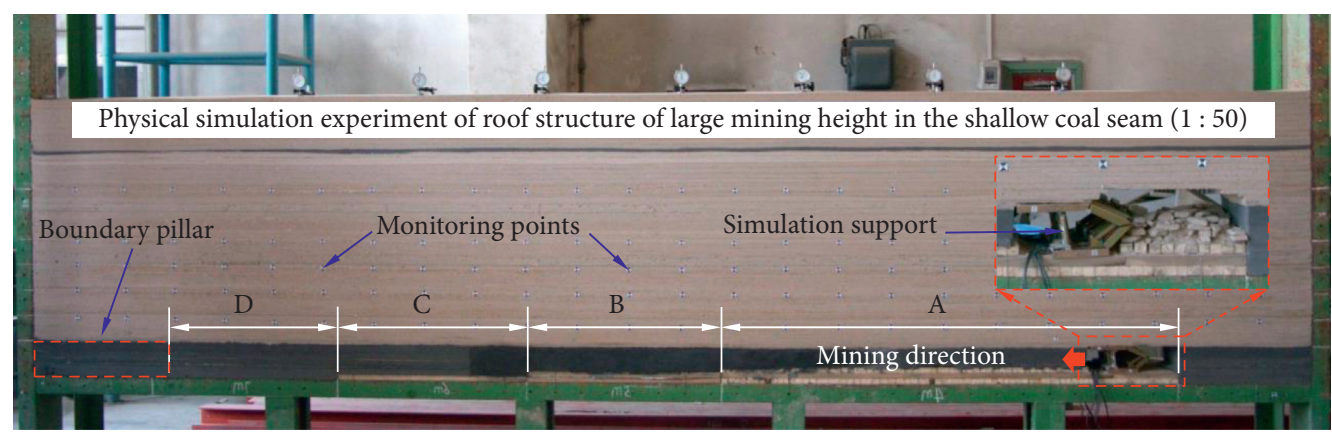

FIgURE 3: The physical simulation model with different mining heights.

TABLE 1: The material ratio of the physical simulation experiment.

\begin{tabular}{|c|c|c|c|c|c|c|c|}
\hline \multirow{2}{*}{ No. } & \multirow{2}{*}{ Lithology } & \multirow{2}{*}{ Thickness $(\mathrm{cm})$} & \multirow{2}{*}{ Material ratio } & \multicolumn{4}{|c|}{ Consumable(kg) } \\
\hline & & & & Sand & Gypsum & $\mathrm{CaCO}_{3}$ & Coal ash \\
\hline 1 & Siltstone & 21.24 & 728 & 297.36 & 8.50 & 33.98 & - \\
\hline 2 & No. 4-4 seam & 1.30 & $20: 1: 5: 20$ & 7.35 & 0.36 & 1.83 & 7.35 \\
\hline 3 & Mudstone & 11.90 & 837 & 168.98 & 6.31 & 14.76 & - \\
\hline 4 & Siltstone & 5.56 & 728 & 77.84 & 2.22 & 8.90 & - \\
\hline 5 & Fine grained sandstone & 8.72 & 737 & 122.08 & 5.23 & 12.21 & - \\
\hline 6 & Siltstone & 24.78 & 728 & 346.92 & 9.91 & 39.65 & - \\
\hline 7 & Fine grained sandstone & 2.38 & 737 & 33.32 & 1.43 & 3.33 & - \\
\hline 8 & Siltstone & 3.82 & 728 & 53.48 & 1.53 & 6.11 & - \\
\hline 9 & Fine grained sandstone & 3.34 & 737 & 46.76 & 2.00 & 4.68 & - \\
\hline 10 & Mudstone & 3.56 & 837 & 50.63 & 1.90 & 4.43 & - \\
\hline 11 & Fine grained sandstone & 5.20 & 737 & 72.80 & 3.12 & 7.28 & - \\
\hline 12 & Mudstone & 5.60 & 837 & 79.64 & 2.99 & 6.97 & - \\
\hline 13 & No. 5-2 seam & $8-14$ & $20: 1: 5: 20$ & $45.20-79.10$ & $2.24-3.92$ & $11.28-19.74$ & $45.20-79.10$ \\
\hline
\end{tabular}



(a)

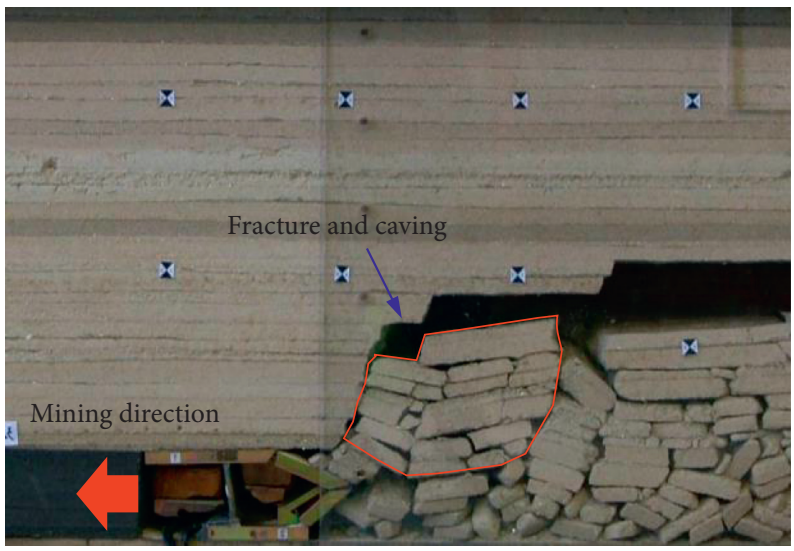

(b)

FIGURE 4: The fracture pattern of the immediate roof: (a) short cantilever beam; (b) short cantilever beam fracture and caving.

0.25 times those of the laboratory tests, whereas Poisson's ratio is 1.2 times that of the laboratory tests. The shear modulus and bulk modulus are calculated by elastic modulus and Poisson's ratio. The mechanical parameters used in UDEC models are listed in Tables 2 and 3. The grids in this numerical model were divided reasonably, referring to the UDEC numerical simulation of overlying strata movement at longwall faces [37, 38].
3.2. Simulation Results Analysis. The simulation results of LW15201 at Zhangjiamao coal mine show that the overlying strata of the longwall face can form the SKS roof structure with the average breaking angle of the KS being $70^{\circ}$. The SKS roof structure is prone to sliding, making the overlying load fully transfer and the roof pressure of the longwall face increase rapidly. Figure 6 shows the "high position oblique step voussoir beam" SKS roof structure. 




FIgURE 5: The thickness of the EIR with mining height.

TABLE 2: Macro-properties used in the UDEC model for simulating rock strata at LW15201.

\begin{tabular}{lcccccccc}
\hline \multirow{2}{*}{ Lithology } & \multicolumn{3}{c}{ Block properties } & \multicolumn{5}{c}{ Contact properties } \\
& Density $\left(\mathrm{kg} / \mathrm{m}^{3}\right)$ & $E(\mathrm{GPa})$ & Poisson's ratio & $K_{\mathrm{n}}(\mathrm{GPa} / \mathrm{m})$ & $K_{\mathrm{s}}(\mathrm{GPa} / \mathrm{m})$ & Cohesion $(\mathrm{MPa})$ & Friction $\left({ }^{\circ}\right)$ & Tensile strength $(\mathrm{MPa})$ \\
\hline Loess & 1700 & 1.9 & 0.23 & 0.5 & 0.3 & 0.2 & 10 & 0.3 \\
Red soil & 1800 & 1.8 & 0.22 & 0.8 & 0.5 & 0.5 & 20 & 0.7 \\
Mudstone & 2470 & 2.0 & 0.26 & 2.5 & 2.2 & 0.7 & 30 & 0.4 \\
Siltstone & 2460 & 7.0 & 0.26 & 2.1 & 1.8 & 0.2 & 36 & 0.6 \\
Fine grained sandstone & 2460 & 9.5 & 0.27 & 2.6 & 1.6 & 0.8 & 32 & 0.5 \\
No. 5-2 seam & 1320 & 1.4 & 0.28 & 2.5 & 1.5 & 0.05 & 25 \\
\hline
\end{tabular}

TABLE 3: Macro-properties used in the UDEC model for simulating rock strata at LW22303.

\begin{tabular}{|c|c|c|c|c|c|c|c|c|}
\hline \multirow{2}{*}{ Lithology } & \multicolumn{3}{|c|}{ Block properties } & \multicolumn{5}{|c|}{ Contact properties } \\
\hline & Density $\left(\mathrm{kg} / \mathrm{m}^{3}\right)$ & $E(\mathrm{GPa})$ & Poisson's ratio & $K_{\mathrm{n}}(\mathrm{GPa} / \mathrm{m})$ & $K_{\mathrm{s}}(\mathrm{GPa} / \mathrm{m})$ & Cohesion (MPa) & Friction $\left({ }^{\circ}\right)$ & Tensile strength (MPa) \\
\hline Aeolian sand & 1850 & 0.5 & - & 0.7 & 0.6 & 0.3 & 20 & 0.4 \\
\hline Fine grained sandstone & 2600 & 8.8 & 0.24 & 2.1 & 1.8 & 0.8 & 35 & 0.5 \\
\hline Coarse grained sandstone & 2700 & 7.3 & 0.28 & 1.8 & 1.5 & 0.7 & 28 & 0.6 \\
\hline Siltstone & 2780 & 7.3 & 0.22 & 1.5 & 0.9 & 0.6 & 35 & 0.7 \\
\hline Mudstone & 2400 & 2.3 & 0.27 & 2.3 & 1.9 & 0.8 & 33 & 0.4 \\
\hline No. 2-2 seam & 1350 & 1.5 & 0.25 & 2.0 & 1.3 & 0.06 & 23 & 0.4 \\
\hline
\end{tabular}

The simulation results of LW22303 at Bulianta coal mine show that the overlying strata of the longwall face can form the DKS roof structure, the lower KS forms the "lower oblique step voussoir beam" structure, and the upper KS forms the "upper voussoir beam" structure.

There are two main types in the DKS roof structure: (1) when the DKS fractures synchronously (Figure 7(a)), the support load of the longwall face caused by the overlying load fully transfer is large, forming large periodic weighting of the longwall face; (2) when the upper KS fractures later than the lower KS (Figure 7(b)), the strata below the upper KS can form bedding separation, the support load of the longwall face is mainly caused by the weight of the lower KS, forming small periodic weighting of the longwall face. During the coal mining process, the large and small roof weighting of the longwall face alternate.

\section{SKS Roof Structure}

4.1. "High Position Oblique Step Voussoir Beam" Structure. For the typical shallow coal seam [39], the thickness of the bedrock is small, and there is only SKS structure in the main roof. According to the field observations of step subsidence [3], the KS theory [14], the physical simulation experiment (Figure 8) [22, 23], and the numerical simulation results, the filling status of the goaf at LFLMH is general filling and the thickness of EIR is large. Thus, the hinge point position of the main roof will move higher, and the overlying strata will form the "high position oblique step voussoir beam" structure, as shown in Figures 8 and 9.

In Figure 9, $h_{1}$ is the thickness of the KS, $\mathrm{m} ; \sum h_{i}$ is the thickness of the EIR, $\mathrm{m} ; m$ is the mining height, $\mathrm{m} ; h_{2}$ is the thickness of the "short cantilever beam," $\mathrm{m} ; h_{3}$ is the 


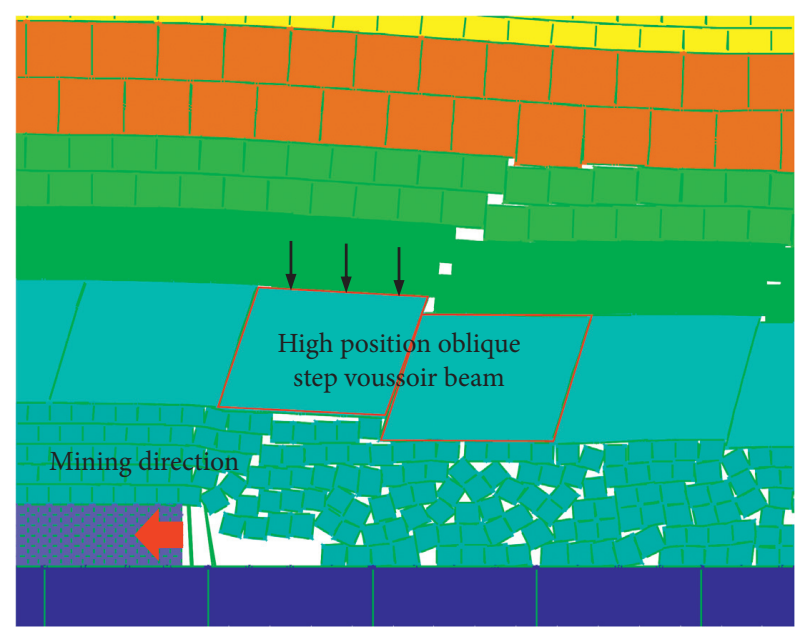

FIgURE 6: The SKS structure of overlying strata.

thickness of easily caving EIR, m; J, M, and N are the key blocks of "high position oblique step voussoir beam" structure; $R_{1}$ is the force on the EIR from the block M, kN; $R_{2}$ is the weight of the "short cantilever beam," $\mathrm{kN} ; R_{3}$ is the weight of easily caving EIR, $\mathrm{kN} ; P_{\mathrm{m}}$ is the support load, $\mathrm{kN}$; $A, B$, and $C$ are the hinge point of the key blocks.

$P_{\mathrm{m}}$ can be calculated using the following formula:

$$
P_{\mathrm{m}}=R_{1}+R_{2}+R_{3} \text {, }
$$

where $R_{1}, R_{2}$, and $R_{3}$ are calculated with support width $b$.

\subsection{Stability Analysis of "High Position Oblique Step Voussoir} Beam" Structure. Based on the "step voussoir beam" structure model [16], the mechanical model of "oblique step" key blocks can be described as in Figure 10.

The key block $\mathrm{N}$ falls entirely on the caving rocks, and the key block $\mathrm{M}$ is supported by the key block $\mathrm{N}$ at point $C$. At this point, the key block $\mathrm{N}$ is compacted; it is desirable that $R_{\mathrm{N}} \approx P_{2}, Q_{\mathrm{B}} \approx 0$. Taking the torque for the key block $\mathrm{M}$ at point $C, \Sigma M_{\mathrm{C}}=0$ :

$$
T\left[\frac{h_{1}}{\sin \beta} \sin (\beta-\theta)-W-0.5 a\right]+P_{1}\left[\frac{L}{2} \cos \theta-d \cot (\beta-\theta)\right]-Q_{\mathrm{A}}\left[L \cos \theta+\frac{h_{1}}{\sin \beta} \cos (\beta-\theta)-d \cot (\beta-\theta)\right]=0
$$

where $T$ is the horizontal squeezing force, $\mathrm{kN} ; \beta$ is the breaking angle of the $\mathrm{KS},{ }^{\circ} ; \theta$ is the rotation angle of the key block $\mathrm{M}, \stackrel{\circ}{;} W$ is the subsidence height of the key block $\mathrm{N}, \mathrm{m}$; $a$ is the height of contact surface, $\mathrm{m} ; P_{1}$ is the sum of the weight of the key block $M$ and the overlying load, $\mathrm{kN}$; $L$ is the length of the key blocks $\mathrm{M}$ and $\mathrm{N}, \mathrm{m}$; $d$ is the step height of the key blocks $M$ and $N, \mathrm{~m} ; Q_{\mathrm{A}}$ is the shear force at point $A$, $\mathrm{kN}$.

Taking the entire vertical force $\Sigma F_{\mathrm{y}}=0$, the equilibrium equation is as follows:

$$
\mathrm{Q}_{\mathrm{A}}+\mathrm{Q}_{\mathrm{B}}+R_{\mathrm{N}}-P_{1}-P_{2}=0
$$

where $Q_{\mathrm{B}}$ is the shear force at point $B, \mathrm{kN} ; R_{\mathrm{N}}$ is the support force for the key block $\mathrm{N}, \mathrm{kN}$; and $P_{2}$ is the sum of the weight of the key block $\mathrm{N}$ and the overlying load, $\mathrm{kN}$.

Substituting $R_{\mathrm{N}} \approx P_{2}$ and $Q_{\mathrm{B}} \approx 0$ into equations (2) and (3), $T$ can be derived, as follows:

$$
\begin{gathered}
T=\frac{\left(h_{1} / \sin \beta\right) \cos (\beta-\theta)+(L / 2) \cos \theta}{\left(h_{1} / \sin \beta\right) \sin (\beta-\theta)-W-0.5 a} P_{1}, \\
Q_{\mathrm{A}} \approx P_{1} .
\end{gathered}
$$

According to the "S-R" stability analysis [40], the "high position oblique step voussoir beam" structure is prone to forming sliding instability, and the condition for preventing the KSS sliding instability is

$$
T \tan \varphi+R_{1} \geq Q_{\mathrm{A}},
$$

where $\tan \varphi$ is the friction coefficient between the blocks and $R_{1}$ is the support force for maintaining the stability of the block $\mathrm{M}, \mathrm{kN}$.

Through equations (4) to (6), the supporting force for maintaining the stability of "high position oblique step voussoir beam" structure is

$$
R_{1}=\left[1-\frac{\left(h_{1} / \sin \beta\right) \cos (\beta-\theta)+(L / 2) \cos \theta}{\left(h_{1} / \sin \beta\right) \sin (\beta-\theta)-W-0.5 a} \tan \varphi\right] P_{1}
$$

where $P_{1}$ consists of the weight of the key block M $\left(R_{\mathrm{G}}\right)$ and the weight of the load layer $\left(\mathrm{R}_{\mathrm{Z}}\right)$ [41]:

$$
\begin{aligned}
& P_{1}=R_{\mathrm{G}}+R_{\mathrm{Z}}, \\
& R_{\mathrm{G}}=b h_{1} L \gamma, \\
& R_{\mathrm{Z}}=K_{\mathrm{G}} b h_{\mathrm{Z}} L \gamma_{\mathrm{Z}},
\end{aligned}
$$

where $b$ is the support width, $\mathrm{m} ; \gamma$ is the bulk density of the bedrock, $\mathrm{kN} / \mathrm{m}^{3} ; K_{\mathrm{G}}(\leq 1)$ is the load transfer coefficient [41]; $h_{\mathrm{Z}}$ is the thickness of the load layer, $\mathrm{m} ; \gamma_{\mathrm{Z}}$ is the bulk density of the load layer, $\mathrm{kN} / \mathrm{m}^{3}$.

Through equations ( 7 ) to (10), $R_{1}$ can be calculated using the following formula:

$$
R_{1}=\left[1-\frac{\left(h_{1} / \sin \beta\right) \cos (\beta-\theta)+(L / 2) \cos \theta}{\left(h_{1} / \sin \beta\right) \sin (\beta-\theta)-W-0.5 a} \tan \varphi\right]
$$

$$
\left(b h_{1} L \gamma+K_{\mathrm{G}} b h_{\mathrm{Z}} L \gamma_{\mathrm{Z}}\right) .
$$






(a)

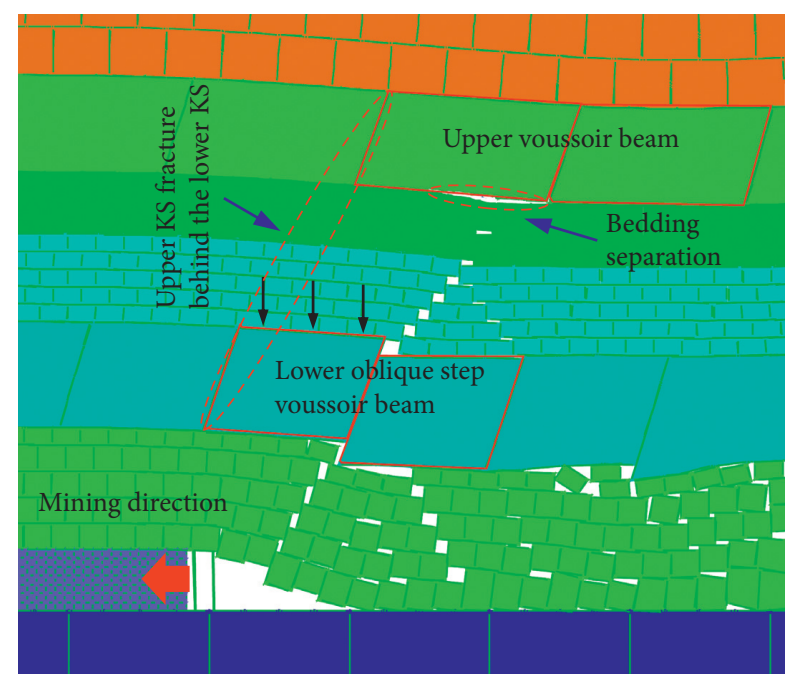

(b)

FIGURE 7: The DKS structure of overlying strata: (a) roof structure during the large periodic weighting; (b) roof structure during the small periodic weighting.

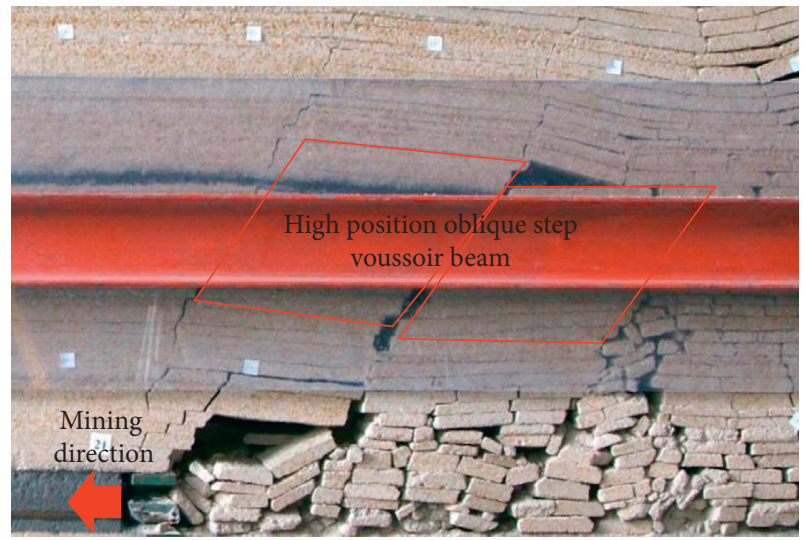

FIGURE 8: The physical simulation photo of the SKS structure.

4.3. Determination of Support Working Resistance at SKS Longwall Face. The composition of the support load of the longwall face is as shown in Figure 11. The weight of the thick $\operatorname{EIR}\left(R_{2}+R_{3}\right)$ is the basic static load, and the instability load of SKS structure $\left(R_{1}\right)$ is an additional dynamic load of the support.

According to the geometric conditions in Figure 11, $R_{2}$ and $R_{3}$ can be calculated using the following formula, respectively:

$$
\begin{aligned}
& R_{2} \approx b l h_{2} \gamma, \\
& R_{3} \approx\left(l_{\mathrm{k}}+\frac{1}{2} h_{3} \cot \alpha\right) b h_{3} \gamma,
\end{aligned}
$$

where $l$ is the length of "short cantilever beam," $\mathrm{m} ; l_{\mathrm{k}}$ is the roof control distance of support, $\mathrm{m}$; and $\alpha$ is the breaking angle of the EIR, .

Based on the mine pressure theory [40], the subsidence height of the key block $\mathrm{N}$ can be calculated using the following formula:

$$
W=m-\left(K_{\mathrm{p}}-1\right) \sum h_{i}
$$

where $K_{\mathrm{p}}$ is the bulking coefficient of the rock mass in the goaf, set to 1.3 .

According to the experimental results [42], take the value of $\tan \varphi$ as 0.5 ; because the values of $\theta$ and $a$ are small, the values of $\theta$ and $0.5 a$ can be set to 0 . Substituting the above parameters into equations (1) and (11) to (14), meanwhile considering the actual efficiency of support, the reasonable support working resistance at SKS longwall face can be calculated using the following formula:

$$
P=\frac{P_{\mathrm{m}}}{\mu}=\frac{1}{\mu}\left\{\left(l h_{2}+l_{\mathrm{k}} h_{3}+\frac{1}{2} h_{3}^{2} \cot \alpha\right) b \gamma+\left[1-\frac{h_{1} \cot \beta+(L / 2)}{2\left(h_{1}-m+0.3 \sum h_{i}\right)}\right]\left(b h_{1} L \gamma+K_{\mathrm{G}} b h_{\mathrm{Z}} L \gamma_{\mathrm{Z}}\right)\right\},
$$

where $\mu$ is the real efficiency of support, which is set to 0.9 . 


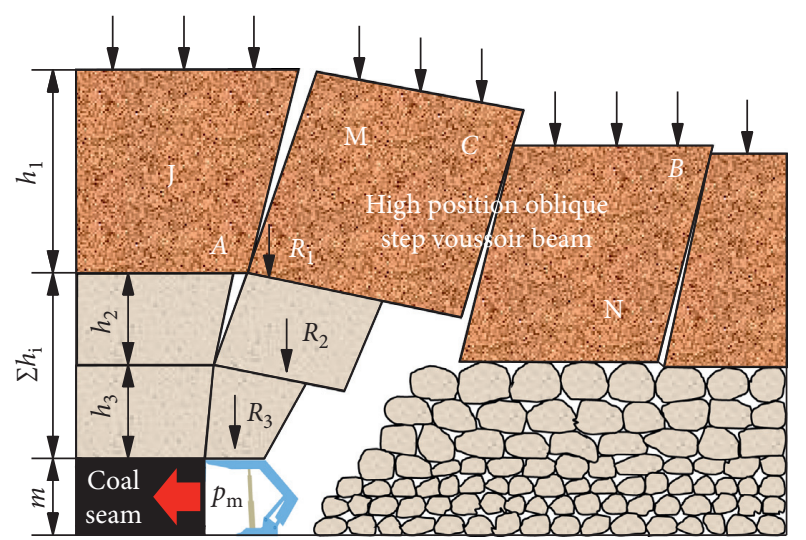

FIgURE 9: The mechanical model of "high position oblique step voussoir beam" structure.

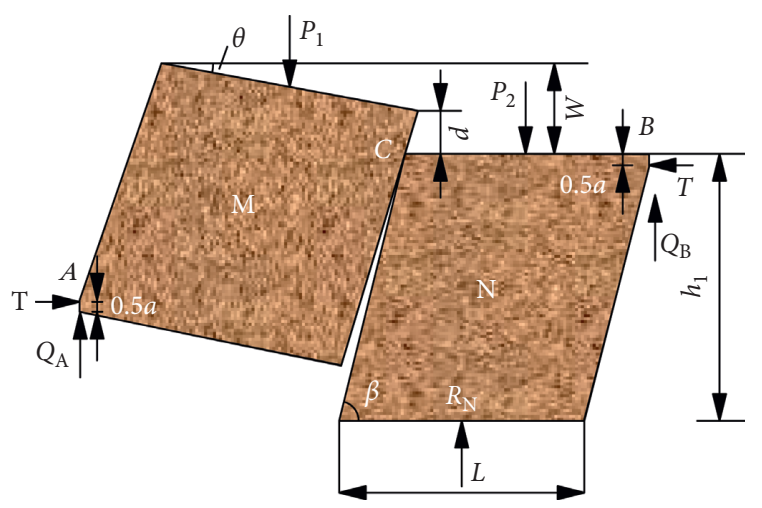

Figure 10: The mechanical model of "oblique step" key blocks.

\section{DKS Roof Structure}

\subsection{DKS Structure and Large-Small Periodic Weighting}

5.1.1. DKS Structure. When the thickness of the bedrock is large, the multi-key strata may exist in the main roof. According to the KS theory, the KS is close to the longwall face, which has a significant impact on the support load. If the spacing of the DKS is small, two KSs interact and generate the DKS structure effect. The spacing that can cause the DKS structure effect is related to the breaking angle of the $\mathrm{KS}$ and the periodic weighting interval, as shown in Figure 12.

When the front hinge joint of the upper KS acts on the lower-key block $M_{1}$, the load of the upper KS can be transferred to the longwall face, according to the geometric conditions in Figure 12; $h_{\text {j.max }}$ can be calculated using the following formula:

$$
h_{\mathrm{j} \cdot \max } \approx L_{1} \tan \beta \text {, }
$$

where $h_{\mathrm{j} \cdot \max }$ is the maximum spacing of the DKS, m, and $L_{1}$ is the length of the lower-key block (approximated to be periodic weighting interval), $\mathrm{m}$.

Therefore, the strength of the periodic weighting of the longwall face is affected if the spacing $h_{\mathrm{j}}$ between lower KS and upper KS satisfies the following formula:



FIgURE 11: The load analysis model of support.

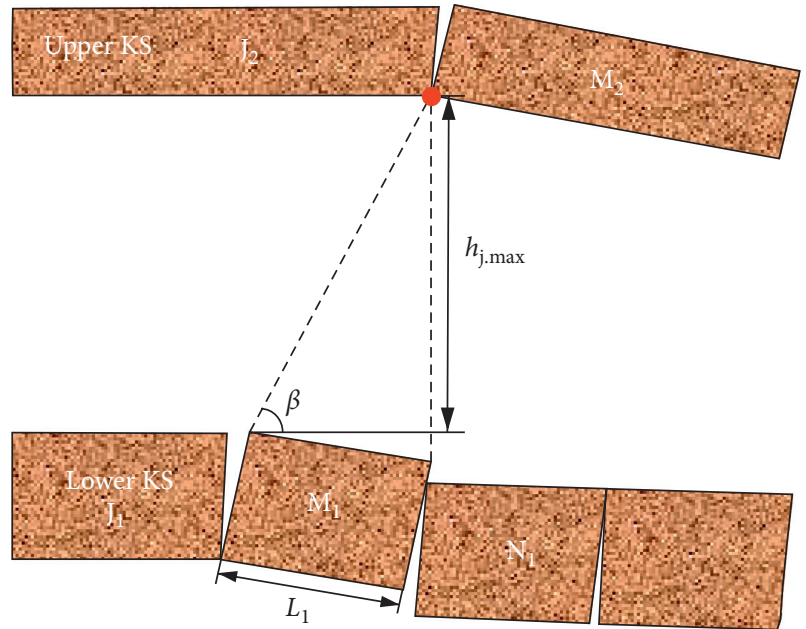

FIgURE 12: The KSS geometric model with DKS structure effect.

$$
h_{j} \leq h_{\mathrm{j} \cdot \max } \approx L_{1} \tan \beta .
$$

Since the periodic weighting interval is generally 10 to $20 \mathrm{~m}$, and the breaking angle of the lower $\mathrm{KS}$ is about $70^{\circ}$ at LFLMH of the shallow coal seam in Shendong mining area [43], according to equation (17), the overlying strata can form the DKS structure effect when $h_{\mathrm{j}} \leq 27 \mathrm{~m}$; the upper key block $\mathrm{M}_{2}$ can influence the stability of the lower KS.

Figure 13 presents the physical simulation experiment results of the longwall mining with large mining height. When the caving EIR does not fully fill the goaf, the key blocks $\mathrm{M}_{1}$ and $\mathrm{N}_{1}$ will present "step subsidence," and the lower KS will form the "oblique step voussoir beam" 




(a)

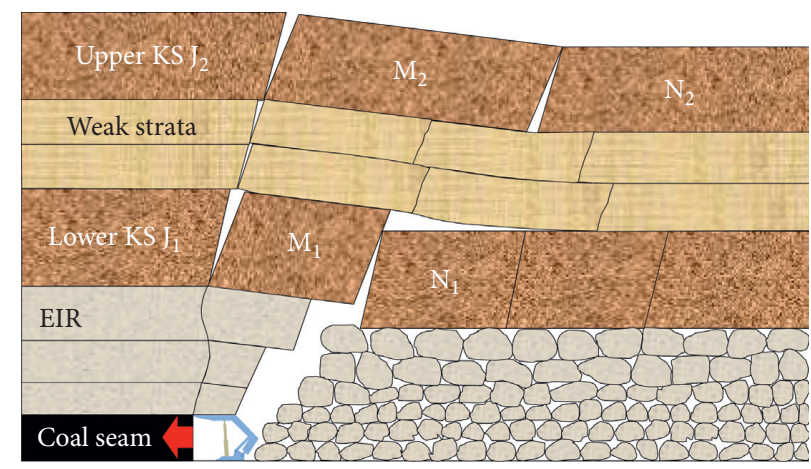

(b)

FIGURE 13: The pattern of DKS structure of the overlying strata: (a) the physical simulation photo of the DKS structure; (b) sketch of the DKS structure.

structure. At this point, the upper KS is supported by the caving EIR, the lower KS, and the weak strata. When the caving EIR reaches fully filling status, the rotation angle of the key block $M_{2}$ is small, and the upper KS will form the "voussoir beam" structure. Therefore, the overlying strata of the longwall face can form the DKS structure of the "oblique step voussoir beam and voussoir beam."

5.1.2. Large Periodic Weighting. When the DKS fractures synchronously, the overlying strata of the longwall face will move fully. The instability load of the upper KS has a dynamic impact on the lower-key block $M_{1}$, and the support load of the longwall face is large, forming a large period weighting. According to the field measurements and physical simulation [43], the large period weighting interval is two times the small period weighting interval, and the roof control of the longwall face is the most challenging work during the large period weighting.

5.1.3. Small Periodic Weighting. When the lower KS is unstable, and the upper KS is stable, the strata below the upper KS will form bedding separations. The upper KS will obstruct the load transfer of overlying strata, and the support load is mainly made up of the weight of the lower-key block $\mathrm{M}_{1}$ and the weak strata. At this point, the support load of the longwall face is small and forms a small periodic weighting of the longwall face.

\subsection{Analysis of the KSS during the Large Periodic Weighting.} When the DKS fractures synchronously, the load of overlying strata will fully act on the longwall face, the support load reaches the largest, and the longwall face can form the large periodic weighting; determining the reasonable support working resistance during the coal mining process should be based on this KSS; the overlying strata structure is shown in Figure 14.
In Figure 14, $h_{1}$ is the thickness of the lower KS, m; $h_{4}$ is the thickness of the weak strata between the upper KS and lower $\mathrm{KS}$ and $h_{5}$ is the thickness of the upper $\mathrm{KS}, \mathrm{m} ; R_{1}$ is the force on the EIR from the block $\mathrm{M}_{1}, \mathrm{kN} ; R_{4}$ is the sum of the weight of the block $\mathrm{M}_{1}$ and weak strata, $\mathrm{kN} ; R_{5}$ is the force on the weak strata from the block $\mathrm{M}_{2}, \mathrm{kN} ; P_{4}$ is the sum of the weight of the key block $\mathrm{M}_{2}$ and the overlying load, $\mathrm{kN} ; L_{1}$ and $L_{2}$ are the lengths of the key blocks $M_{1}$ and $M_{2}$, respectively, $\mathrm{m} ; W_{1}$ and $W_{2}$ are the subsidence heights of the key blocks $\mathrm{N}_{1}$ and $\mathrm{N}_{2}$, respectively, $\mathrm{m}$; and $\theta$ is the rotation angle of the key block $M_{1}$, .

As shown in Figure 14, the support load is mainly made up of the basic load provided by the static load of the EIR and the additional load offered by the instability dynamic load of the "lower oblique step voussoir beam" structure. The effect of upper KS is reflected by its instability load acting on lower KS and leads to an increase in the support load.

The composition of the support load also by $R_{1}, R_{2}$, and $R_{3}$ can be calculated using equation (1). The load acting on the EIR from the key block $M_{1}$ can be calculated using the following formula:

$$
R_{1}=\left[1-\frac{\left(h_{1} / \sin \beta\right) \cos (\beta-\theta)+\left(L_{1} / 2\right) \cos \theta}{\left(h_{1} / \sin \beta\right) \sin (\beta-\theta)-W_{1}-0.5 a} \tan \varphi\right] P_{3} \text {, }
$$

where $P_{3}$ is the sum of the weight of the key block $M_{1}$ and the overlying load, $\mathrm{kN}$.

Since the DKS fractures synchronously, the instability load of the upper KS and the weight of weak strata will simultaneously act on the lower KS. Therefore, $P_{3}$ includes the sum of the weight of the key block $M_{1}$ and the weak strata $\left(R_{4}\right)$, as well as the load acting on the weak strata from the key block $\mathrm{M}_{2}\left(R_{5}\right)$.

$R_{4}$ can be calculated using the following formula:

$$
R_{4}=\left(h_{1}+h_{4}\right) b L_{1} \gamma
$$




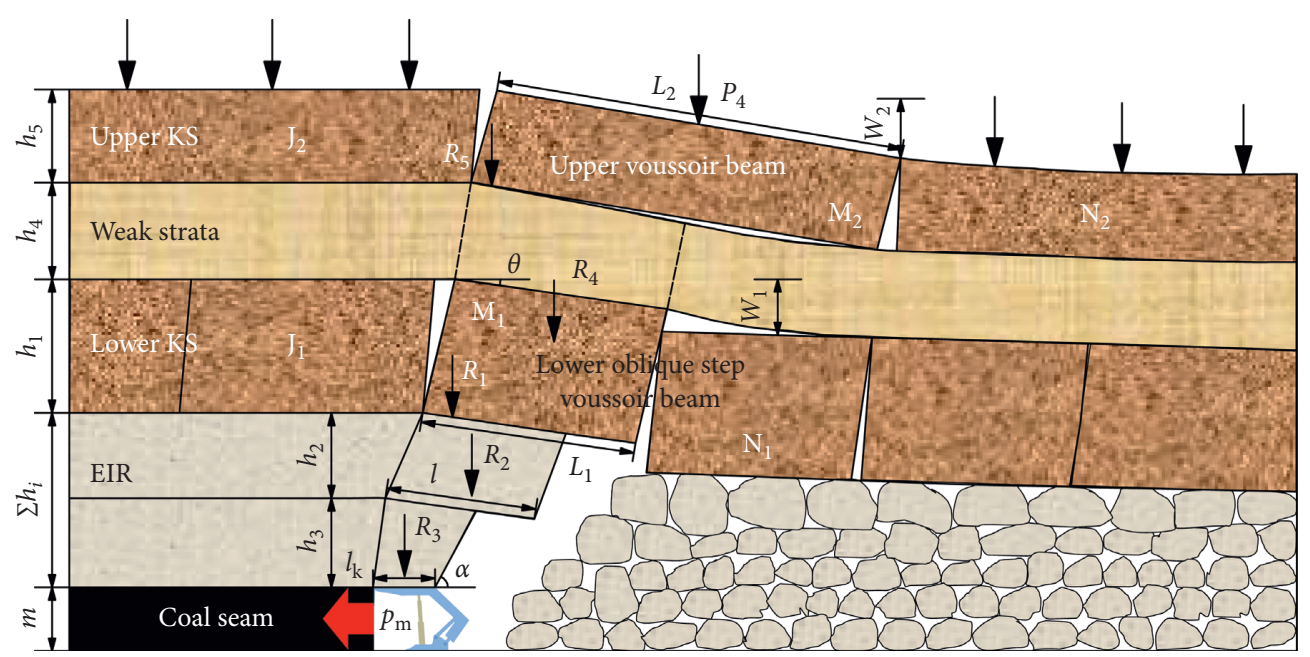

FIgURE 14: The mechanical model of DKS structure during the large periodic weighting.

According to Huang [43], $R_{5}$ can be calculated using the following formula:

$$
R_{5}=\left[2+\frac{L_{2} \cot (\varphi+\beta-\theta)}{2\left(h_{5}-W_{2}\right)}\right] P_{4},
$$

where $\varphi$ is the friction between the blocks $\left({ }^{\circ}\right)$, and $P_{4}$ can be determined by the calculation method for $P_{1}$.
$P_{3}$ can be calculated using equations (19) and (20):

$$
P_{3}=R_{4}+R_{5}=\left(h_{1}+h_{4}\right) b L_{1} \gamma+\left[2+\frac{L_{2} \cot (\varphi+\beta-\theta)}{2\left(h_{5}-W_{2}\right)}\right] P_{4}
$$

Through equations (1), (12), (13), (18), and (21), the support working resistance during the large periodic weighting can be calculated using the following formula:

$$
\begin{aligned}
P_{\mathrm{m} \cdot \max }= & R_{1}+R_{2}+R_{3}=\left(l h_{2}+l_{\mathrm{k}} h_{3}+\frac{1}{2} h_{3}^{2} \cot \alpha\right) b \gamma+\left[1-\frac{\left(h_{1} / \sin \beta\right) \cos (\beta-\theta)+\left(L_{1} / 2\right) \cos \theta}{\left(h_{1} / \sin \beta\right) \sin (\beta-\theta)-W_{1}-0.5 a} \tan \varphi\right] \\
& \cdot\left[\left(h_{1}+h_{4}\right) b L_{1} \gamma+2 P_{4}+\frac{L_{2} \cot (\varphi+\beta-\theta)}{2\left(h_{5}-W_{2}\right)} P_{4}\right] .
\end{aligned}
$$

\subsection{Analysis of the KSS during the Small Periodic Weighting.} When the lower KS is unstable, and the upper KS is stable, upper and lower KS form delamination. Figure 15 shows the overlying strata structure of the longwall face. The load transfer of the overlying strata is obstructed, and the longwall face can form the small periodic weighting. At this point, the support load is mainly made up of the instability load of the lower KS and the weight of the EIR.

During the small periodic weighting of the longwall face, the load of the lower-key block $M_{1}$ is the only weight of the weak strata, and $P_{3}$ can be calculated using the following formula:

$$
P_{3}=R_{4}=\left(h_{1}+h_{4}\right) b L_{1} \gamma
$$

Combining equations (1), (12), (13), (18), and (23), the support working resistance during the small periodic weighting can be calculated using the following formula:

$$
P_{\mathrm{m} \cdot \min }=R_{1}+R_{2}+R_{3}=\left(l h_{2}+l_{\mathrm{k}} h_{3}+\frac{1}{2} h_{3}^{2} \cot \alpha\right) b \gamma+\left[1-\frac{\left(h_{1} / \sin \beta\right) \cos (\beta-\theta)+\left(L_{1} / 2\right) \cos \theta}{\left(h_{1} / \sin \beta\right) \sin (\beta-\theta)-W_{1}-0.5 a} \tan \varphi\right]\left(h_{1}+h_{4}\right) b L_{1} \gamma
$$

5.4. Determination of Support Working Resistance at DKS Longwall Face. According to the above analysis, if the DKS structure effect is generated in overlying strata, the determination of support working resistance should be based on 




FIGURE 15: The mechanical model of DKS structure during the small periodic weighting.

overlying strata load during the large periodic weighting, and the values of $W_{1}$ and $W_{2}$ can be calculated by equation (14). Considering the real efficiency of support, the reasonable support working resistance at DKS longwall face can be calculated using the following formula:

$$
P=\frac{P_{\mathrm{m} \cdot \max }}{\mu}=\frac{1}{\mu}\left\{\left(l h_{2}+l_{\mathrm{k}} h_{3}+\frac{1}{2} h_{3}^{2} \cot \alpha\right) b \gamma+\left[1-\frac{h_{1} \cot \beta+\left(L_{1} / 2\right)}{2\left(h_{1}-m+0.3 \sum h_{i}\right)}\right] \cdot\left[\left(h_{1}+h_{4}\right) b L_{1} \gamma+2 P_{4}+\frac{L_{2} \cot (\varphi+\beta)}{2\left(h_{5}-m+0.3 \sum h_{i}\right)} P_{4}\right]\right\}
$$

\section{Engineering Applications}

6.1. Calculation of Support Working Resistance at SKS Longwall Face. According to the borehole column histogram and KS identification of LW22406 at Halagou coal mine, an SKS structure is found in overlying strata [44]. The correctness of the calculation formula of support working resistance at the SKS longwall face can be verified with the parameters of LW22406. Based on the geological data, mining conditions, and the simulation experiment results, the following parameters are determined: the mining height $\mathrm{m}$ is $5.2 \mathrm{~m}$, the thickness $h_{1}$ of the KS is $10 \mathrm{~m}$, the bulk density $\gamma$ of the bedrock is $25 \mathrm{kN} / \mathrm{m}^{3}$, the bulk density $\gamma_{\mathrm{Z}}$ of the load layer is $25 \mathrm{kN} / \mathrm{m}^{3}$, the length $L$ of the key block (approximated to be periodic weighting interval) is $12.1 \mathrm{~m}$, the thickness $h_{\mathrm{z}}$ of the load layer is $10 \mathrm{~m}$, the thickness $\sum h_{i}$ of the immediate roof is $15 \mathrm{~m}$, the length $l$ of the "short cantilever beam" is $10.5 \mathrm{~m}$, and the values of $h_{2}$ and $h_{3}$ are $13 \mathrm{~m}$ and $2 \mathrm{~m}$, respectively. The LW22406 was equipped with ZY12000/25.5/55D-type supports, and the support width $b$ is $1.75 \mathrm{~m}$, the roof control distance $l_{\mathrm{k}}$ of support is $5.0 \mathrm{~m}$, the breaking angle $\beta$ of the $\mathrm{KS}$ is $65^{\circ}$ on average, the breaking angle $\alpha$ of the lower EIR is $60^{\circ}$ on average, according to engineering experience, the value of $K_{\mathrm{G}}$ is 0.38 .

Substituting the above parameters into equation (15), the reasonable support working resistance of the longwall face can be calculated as $10620 \mathrm{kN}$. According to the monitoring data of support load at LW22406 (Figure 16), the average support working resistance during the periodic weighting is
$84 \%$ to $92 \%$ of rated support working resistance $(12000 \mathrm{kN})$, which is very close to the support working resistance in the field practice, indicating that the calculation formula can provide some guidance for support selection.

6.2. Calculation of Support Working Resistance at DKS Longwall Face. Through the KS identification with three borehole column histograms of LW22303 at Bulianta coal mine in Shendong mining area, the DKS structure is found in the overlying strata [45]. The correctness of the calculation formula of support working resistance at the DKS longwall face can be verified with the parameters of LW22303. Based on the geological data, mining conditions, and the simulation experiment results, the following parameters are determined: the mining height $m$ is $6.8 \mathrm{~m}$, the bulk density $\gamma$ of the bedrock is $25 \mathrm{kN} / \mathrm{m}^{3}$, the length $L_{1}$ of the lower-key block is $13.2 \mathrm{~m}$, the length $L_{2}$ of the upper key block is $25 \mathrm{~m}$, the thickness $\sum h_{i}$ of the immediate roof is $17.3 \mathrm{~m}$, the length $l$ of the "short cantilever beam" is $11.8 \mathrm{~m}$, the values of $h_{1}$ to $h_{5}$ are $10.2 \mathrm{~m}, 14 \mathrm{~m}, 3.3 \mathrm{~m}, 4.6 \mathrm{~m}$, and $8.7 \mathrm{~m}$, respectively, and the value of $P_{4}$ is $1725 \mathrm{kN}$. The LW22303 was equipped with ZY16800/32/70D-type supports, and the support width $b$ is $2.05 \mathrm{~m}$, the roof control distance $l_{\mathrm{k}}$ of support is $6.62 \mathrm{~m}$, the breaking angle $\beta$ of the $\mathrm{KS}$ is $65^{\circ}$ on average, the friction angle $\varphi$ between the blocks is about $27^{\circ}$, and the breaking angle $\alpha$ of the lower EIR is $60^{\circ}$ on average. 


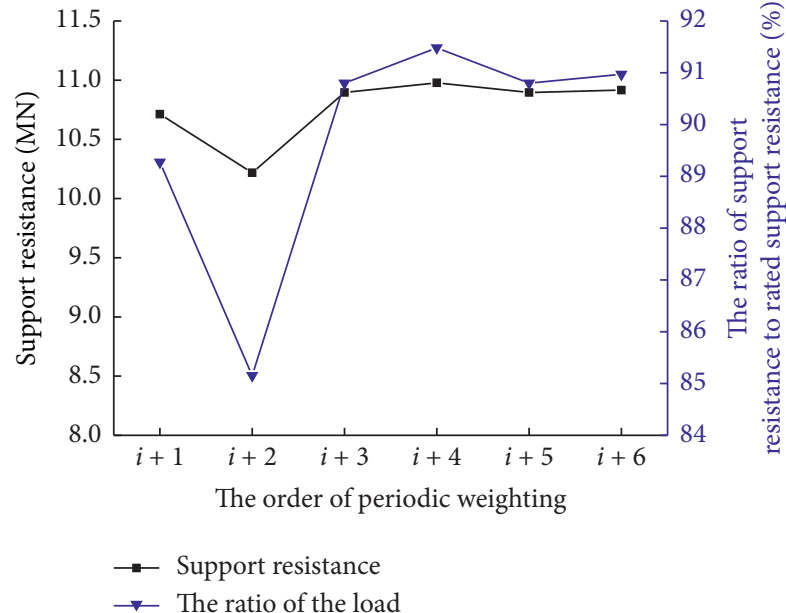

FIGURE 16: The average support working resistance during the periodic weighting at LW22406.

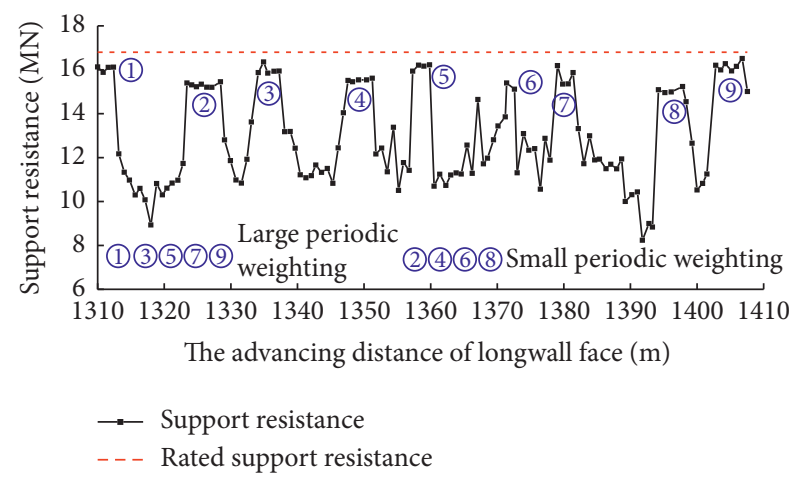

FIGURE 17: The average support working resistance during the coal mining process at LW22303.

Substituting the above parameters into equation (25), the reasonable support working resistance of the longwall face can be calculated as $15860 \mathrm{kN}$. According to the field measurements, the average support working resistance during the coal mining process is shown in Figure 17. The support working resistance shows the large-small alternate phenomenon, which verifies the correctness of the KSS analysis, and the theoretical calculation result is very close to the support working resistance during the large periodic weighting. The rated support working resistance of supports in the field is $16800 \mathrm{kN}$, which meets the requirements for roof control.

\section{Conclusions}

Based on the physical simulation experiment and the numerical simulation, the caving characteristics and the cantilever fracture pattern of the EIR at LFLMH were analyzed, and the SKS and DKS roof structures models in the shallow coal seam were constructed. Through the mechanical analysis, the mechanism of roof weighting at LFLMH was revealed, and the calculation formulas of the reasonable support working resistance of the longwall face were proposed. The conclusions are as follows:

(1) The roof caving space increases at LFLMH in the shallow coal seam. Some lower main roof is challenging to form the hinged structure, and it can fill the goaf. The thickness of the immediate roof increases largely and presents a "short cantilever beam" structure commonly. The main roof can form a high position hinged structure. The studies show the ratios of the immediate roof static load to the increase in roof pressure. The value of the dynamic load is small, and the overall roof pressure of the longwall face is large.

(2) According to the filling status of the EIR to goaf, the EIR can be divided into "fully filling type" and "general filling type." The fully filling of goaf can form the stable "voussoir beam" structure with relatively small roof weighting of the longwall face. The general filling of goaf can form the "high position oblique step voussoir beam" structure with strong roof weighting of the longwall face, and this KSS is the universal form at LFLMH in the shallow coal seam.

(3) When the overlying strata only have SKS of LFLMH in the shallow coal seam, the main roof can form the "high position oblique step voussoir beam" structure, and the sliding of the KSS is the root cause to roof weighting of the longwall face that increases rapidly. When there is DKS in overlying strata, the "oblique step voussoir beam, and voussoir beam" structure can be formed. The instability of the DKS synchronously causes large periodic weighting, and the instability of the lower KS causes small period weighting. During the coal mining process, the large and small roof weighting of the longwall face alternate. Besides, the calculation formulas of the reasonable support working resistance were proposed, which can provide a reference for the support selection and roof control at LFLMH in the shallow coal seam.

\section{Data Availability}

The data used to support the findings of this study are included within the paper. Other data used to support the findings of this study are available from the corresponding author upon request.

\section{Conflicts of Interest}

The authors declare that there are no conflicts of interest regarding the publication of this paper.

\section{Acknowledgments}

This work was supported by the National Natural Science Foundation of China (No. 52074211 and No. 51674190) and the Natural Science Basic Research Program of Shaanxi (No. 2019JLP-08). 


\section{References}

[1] S. Tu and Y. Yuan, Theory and Practice of Large Mining High Fully Mechanized Mining in Thick Seam, China University of Mining and Technology Press, Xuzhou, China, 2012.

[2] Z. Wen, E. Xing, S. Shi, and Y. Jiang, "Overlying strata structural modeling and support applicability analysis for large mining-height stopes," Journal of Loss Prevention in the Process Industries, vol. 57, pp. 94-100, 2019.

[3] J. Ju and J. Xu, "Surface stepped subsidence related to top-coal caving longwall mining of extremely thick coal seam under shallow cover," International Journal of Rock Mechanics and Mining Sciences, vol. 78, pp. 27-35, 2015.

[4] Y. Yuan, "System dynamics model of the support-surrounding rock system in fully mechanized mining with large mining height face and its application," International Journal of Mining Science and Technology, vol. 23, no. 6, pp. 879-884, 2013.

[5] S.-h. Tu, Y. Yong, Y. Zhen, X.-T. Ma, and W. Qi, "Research situation and prospect of fully mechanized mining technology in thick coal seams in China," Procedia Earth and Planetary Science, vol. 1, no. 1, pp. 35-40, 2009.

[6] B. Li, Y. Liang, and Q. Zou, "Determination of working resistance based on movement type of the first subordinate key stratum in a fully mechanized face with large mining height," Energy Science and Engineering, vol. 7, no. 3, pp. 777-798, 2019.

[7] P. Wu, H. Chen, and R. Long, "Relationship between coal output and safety in China," Disaster Advances, vol. 5, no. 4, pp. 551-556, 2012.

[8] X. Yuan, "The characters and trend of accidents in the coal mining in China," Disaster Advances, vol. 5, no. 4, pp. 867870, 2012.

[9] Q.-S. Bai, S.-H. Tu, M. Chen, and C. Zhang, "Numerical modeling of coal wall spall in a longwall face," International Journal of Rock Mechanics and Mining Sciences, vol. 88, pp. 242-253, 2016.

[10] G. Saeedi, K. Shahriar, B. Rezai, and C. Karpuz, "Numerical modelling of out-of-seam dilution in longwall retreat mining," International Journal of Rock Mechanics and Mining Sciences, vol. 47, no. 4, pp. 533-543, 2010.

[11] C. Zhang, I. Canbulat, B. Hebblewhite, and C. R. Ward, "Assessing coal burst phenomena in mining and insights into directions for future research," International Journal of Coal Geology, vol. 179, pp. 28-44, 2017.

[12] Z. Li, J. Xu, S. Yu, J. Ju, and J. Xu, "Mechanism and prevention of a chock support failure in the longwall top-coal caving faces: a case study in Datong coalfield, China," Energies, vol. 11, no. 2, pp. 1-17, 2018.

[13] W. Guo, H. Wang, G. Dong, and L. Li, "A case study of effective support working resistance and roof support technology in thick seam fully-mechanized face mining with hard roof conditions," Sustainability, vol. 9, no. 6, 2017.

[14] M. Qian, X. Miao, and J. Xu, Key Strata Theory in Ground Control, China University of Mining and Technology Press, Xuzhou, China, 2003.

[15] Q. Huang, "Structural analysis of main roof stability during first weighting in long wall face," Chinese Journal of Rock Mechanics and Engineering, vol. 17, no. 5, pp. 521-526, 1998.

[16] Q. Huang, M. Qian, and P. Shi, "Structural analysis of main roof stability during periodic weighting in long wall face," Journal of China Coal Society, vol. 24, no. 6, pp. 581-585, 1999.

[17] Q. Huang and P. Zhang, "Study on dynamic load distribution on key roof block in shallow seam," Chinese Journal of Rock
Mechanics and Engineering, vol. 23, no. 24, pp. 4179-4182, 2004.

[18] J. Ju and J. Xu, "Structural characteristics of key strata and strata behaviour of a fully mechanized longwall face with 7.0 m height chocks," International Journal of Rock Mechanics and Mining Sciences, vol. 58, pp. 46-54, 2013.

[19] J. Ju, J. Xu, and Q. Wang, "Cantilever structure moving type of key strata and its influence on ground pressure in large mining height work face," Journal of China Coal Society, vol. 36, no. 12, pp. 2115-2120, 2011.

[20] S. Yan, X. Yin, H. Xu, G. Xu, Q. Liu, and L. Yu, "Roof structure of short cantilever-articulated rock beam and calculation of support resistance in full-mechanized face with large ming height," Journal of China Coal Society, vol. 36, no. 11, pp. 1816-1820, 2011.

[21] P. Gong, "Mechanical model study on roof control for fullymechanized coal face with large mining height," Chinese Journal of Rock Mechanics and Engineering, vol. 27, no. 1, pp. 193-198, 2008.

[22] Q. Huang, L. Ma, B. Dong, and B. Shen, "Research on equivalent immediate roof and roof structure of large mining height face," Journal of Xi'an University of Science and Technology, vol. 35, no. 5, pp. 541-546, 2015.

[23] Q. Huang and P. Tang, "Roof structure analysis on large mining height longwall face in shallow coal seam," Journal of Mining and Safety Engineering, vol. 34, no. 2, pp. 282-286, 2017.

[24] Q. Huang, Y. He, and J. Cao, "Experimental investigation on crack development characteristics in shallow coal seam mining in China," Energies, vol. 12, no. 7, 2019.

[25] P. Gong, Research on Surrounding Rock Control Theory and its Application in Large Mining Height Working Face, Coal industry Press, Beijing, China, 2006.

[26] Y. Yuan, S. Tu, X. Zhang, and B. Li, "Dynamic effect and control of key strata break of immediate roof in fully mechanized mining with large mining height," Shock and Vibration, vol. 2015, Article ID 657818, 11 pages, 2015.

[27] F.-f. Wu, C.-y. Liu, and J.-x. Yang, "Mode of overlying rock roofing structure in large mining height coal face and analysis of support resistance," Journal of Central South University, vol. 23, no. 12, pp. 3262-3272, 2016.

[28] M. Zhang, Y. Zhang, M. Ji, H. Guo, and H. Li, "Research on physical similarity simulation of mining uphill and downhill at the large-angle working face," Advances in Civil Engineering, vol. 2019, Article ID 7696752, 19 pages, 2019.

[29] Z. Yuan, Y. Shao, and Z. Zhu, "Similar material simulation study on protection effect of steeply inclined upper protective layer mining with varying interlayer distances," Advances in Civil Engineering, vol. 2019, Article ID 9849635, 14 pages, 2019.

[30] Y. Niu, Z. Li, B. Kong et al., "simulation study on the characteristics of the electric potential response to coal mining," Journal of Geophysics and Engineering, vol. 15, no. 1, pp. 42-50, 2018.

[31] H. Dai, X. Lian, J. Liu, and Y. Liu, "Model study of deformation induced by fully mechanized caving below a thick loess layer," International Journal of Rock Mechanics and Mining Sciences, vol. 47, no. 6, pp. 1027-1033, 2010.

[32] Y. Liu, F. Zhou, L. Liu, C. Liu, and S. Hu, “An experimental and numerical investigation on the deformation of overlying coal seams above double-seam extraction for controlling coal mine methane emissions," International Journal of Coal Geology, vol. 87, pp. 139-149, 2011. 
[33] H. Yan, J. Zhang, S. Zhang, and N. Zhou, "Physical modeling of the controlled shaft deformation law during the solid backfill mining of ultra-close coal seams," Bulletin of Engineering Geology and the Environment, vol. 78, no. 5, pp. 3741-3754, 2019.

[34] W. Zhu, Y. Li, S. Li, S. Wang, and Q. Zhang, "Quasi-threedimensional physical model tests on a cavern complex under high in-situ stresses," International Journal of Rock Mechanics and Mining Sciences, vol. 48, no. 2, pp. 199-209, 2011.

[35] N. Mohammad, D. J. Reddish, and L. R. Stace, "The relation between in situ and laboratory rock properties used in numerical modelling," International Journal of Rock Mechanics and Mining Sciences, vol. 34, no. 2, pp. 289-297, 1997.

[36] M. Cai, M. He, and D. Liu, Rock Mechanics and Engineering, Science Press, Beijing, China, 2013.

[37] F. Gao, D. Stead, and J. Coggan, "Evaluation of coal longwall caving characteristics using an innovative UDEC Trigon approach," Computers and Geotechnics, vol. 55, pp. 448-460, 2014.

[38] C. Xu, Q. Fu, X. Cui, K. Wang, Y. Zhao, and Y. Cai, “Apparent-depth effects of the dynamic failure of thick hard rock strata on the underlying coal mass during underground mining," Rock Mechanics and Rock Engineering, vol. 52, no. 5, pp. 1565-1576, 2019.

[39] Q. Huang, "Ground pressure behavior and definition of shallow seams," Chinese Journal of Rock Mechanics and Engineering, vol. 21, no. 8, pp. 1174-1177, 2002.

[40] M. Qian, P. Shi, and J. Xu, Mine Pressure and Ground Control, China University of Mining and Technology Press, Xuzhou, China, 2010.

[41] Q. Huang, "Study on load transmitting factor of thick sandy soil on key roof stratum during first weighting in shallow seam," Rock and Soil Mechanics, vol. 26, no. 6, pp. 881-883, 2005.

[42] Q. Huang, "Experimental investigation on friction and squeezing of roof structure key blocks corner upon long-wall face," Journal of University of Science and Technology Beijing, vol. 12, no. 2, pp. 102-105, 2005.

[43] Q. Huang, Ground Control of Longwall Mining in the Shallow Coal Seam, Science Press, Beijing, China, 2018.

[44] T. Zhang, Y. Zhao, G. Zhu, S. Wang, and Z. Jiao, "A multicoupling analysis of mining-induced pressure characteristics of shallow-depth coal face in Shendong mining area," Journal of China Coal Society, vol. 41, no. S2, pp. 287-296, 2016.

[45] J. Xu, W. Zhu, X. Wang, and M. Yi, "Classification of key strata structure of overlying strata in shallow coal seam," Journal of China Coal Society, vol. 34, no. 7, pp. 865-870, 2009. 